\section{A NINETEENTH-CENTURY BOTANIST}

Asa Gray, 1810-1888

By Prof. A. Hunter Dupree. Pp. $x+505+9$ plates. (Cambridge, Mass.: The Belknap Press of Harvard University Press; London: Oxford University Press, 1959.) 60s. net.

$\mathrm{T}$ HE story of Asa Gray is told against a background of history concerned with the intellectual development of America during the nineteenth century. These pages should appeal not only to botanists, who know of its subject as one of the pioneers in the study of the geographical distribution of the American flora, but also to all those interested in the growth of the fruitful scientific collaboration between the New World and the old in which Asa Gray played a notable part.

Born in 1810 of farming stock, Asa Gray was reared in the beautiful valley of Sanquoit and worked in the bark mill of his father's tannery. He was eighteen when plants caught up his interest, and he began to make a herbarium during his apprenticeship, for like so many of the earlier botanists he was educated as a medical practitioner. At the age of twenty-eight he was appointed professor of botany to the new University of Michigan and was enabled to visit Europe, which gave him the opportunity of forming the contacts with William and Joseph Hooker, George Bentham, Lyell and Charles Darwin that were to have a profound influence upon his subsequent career as an investigator.

While the author of this work emphasizes how Gray's scientific activities were chained to the results of American expansion and exploration, these nevertheless provided both the opportunities and the means. It was Asa Gray's good fortune to discover in the eastern States single representatives of Japanese genera previously regarded as monotypic, thus confirming his conclusions that while the European connexions are most marked on the side of the American continent nearer Europe, those with Asia are greatest on the remote side. It was these observations and his wide grasp of the North American floristics which attracted the attention of the Hookers and later of Darwin when he turned his attention to the botanical field.

From these pages we get the impression of their subject as a vigorous character, but quite incapable of estimating what he could, in fact, accomplish so that during his more active period 'the incomplete works of Asa Gray' continued to augment. It is an interesting sidelight on his personality that antagonism to the views of Agassiz would seem to have been an important stimulus, just as it was Alphonso Woods publications that appear to have provided the requisite catalyst for Gray to write his "Manual", that was his most important work, and which might otherwise never have been completed.

The Gray Herbarium was a vast collection that bore tribute to his drive; and the difficulties he had with the collectors, upon whom he relied for the new plants he described, are well portrayed as well as the impediments that these pioneer workers had to overcome in the tasks of identification.

The author of a biography may be forgiven a partiality for his subject and to such bias we may perhaps attribute the statement that Gray "shewed the qualities of mind and character necessary to riso to Darwin's level". But even though the reader may scruple to accept this assessment he cannot but be grateful to the author for this fully documented presentation of the man and his environment.

E. J. SAlisbURY

\section{MASTER OF MICROBIOLOGY}

Albert Jan Kluyver

His Life and Work: Biographical Memoranda, Selected Papers, Bibliography and Addenda. Edited by A. F. Kamp, J. W. M. La Rivière and W. Verhoeven. Pp. $x v+567$. (Amsterdam: North-Holland Publishing Co. : New York : Interscience Publishers, Inc., 1959.) $80 s$.

7 HIS book contains a record of the life and work of a great microbiologist--perhaps the last we shall see of those encyclopædic men whose field was the study of micro-organisms as a whole. Microorganisms have an inereasing role in human activities : as agents of soil fertility and in the production of prophylactic, therapeutic and other economically important materials, and as agents in animal and plant diseases and in the spoilage of stored products. The utilization and control of micro-organisms will be increasingly important as populations grow, with their increasing demand for food and for the prevention of disease. Applied physics may steal the headlines for a while, but when all is said, the problems of food production and of health will remain, and in these micro-organisms must play an important part. The concepts of the 'unity of biochemistry' and of 'comparative biochemistry' which Kluyver enunciated so clearly are cardinal in modern biological studies. Micro-organisms multiply quickly and we now know that it is often possible by studying them to gain information of general biological importance more easily and rapidly than by studying more complex organisms. Kluyver's work in microbiology is an example par excellence of that interweaving of biochemistry and biology which is now proving so fruitful in biological studies. The line of Dutch microbiologists such as Leeuwenhoek, Beijerinck and Kluyver forms one of the great arteries of microbiology; this school has been particularly concerned with fundamental studies of microbial physiology. Another equally important line comes, of course, from the Pasteur school, which developed particularly the study of disease-producing organisms and the prevention of their effects. Both lines of development lead, in the end, to study of the biochemistry of the modes of action of specific micro-organisms. An important feature of the work of the Dutch school has always been the study of micro-organisms in general, of what they do and how they do it : general microbial physiology.

The book is divided into three parts ; most of it is in English.

Part 1. Biographical memoranda. This begins (pp. 3-67; illustrated by 23 photographs) by giving the outline of Kluyver's life, with a very interesting section about Kluyver as seen by his pupils. There follows (pp. 68-155) a masterly survey by C. B. van Niel of Kluyver's contribution to microbiology and biochemistry. This part closes with two moving funeral orations.

Part 2. Selected papers (pp. 165-524). The papers selected are, with two exceptions, those of which Kluyver was the sole author. They are mainly the 